ARTIFICIAL SATELLITES, Vol. 49, No. 1 - 2014
DOI: 10.2478/arsa-2014-0005

\title{
ASSESSMENT STUDY OF STATIC-PPP CONVERGENCE BEHAVIOUR USING GPS, GLONASS AND MIXED GPS/GLONASS OBSERVATIONS
}

\author{
Ashraf Farah \\ Associate Professor, College of Engineering, Aswan University, Aswan, Egypt. \\ ashraf_farah@aswu.edu.eg
}

\begin{abstract}
Precise Point Positioning (PPP) has been used for the last decade as a cost-effective alternative for the ordinary DGPS-Differential GPS with an estimated precision sufficient for many applications. PPP requires handling different types of errors using proper models. PPP precision varies with the use of observations from different satellite systems (GPS, GLONASS and mixed GPS/GLONASS) and the duration of observations. This research presents an evaluation study for the variability of Static-PPP precision based on different observation types (GPS, GLONASS and mixed observations) and observation duration. It can be concluded that Static-PPP solution using mixed observations is offering similar accuracy as the one using GPS-only observations and saving 15 minutes observation time. For 30 minutes of observation duration, mixed observations offers improvement percentages of $14 \%$, $26 \%$ and $25 \%$ for latitude, longitude and height respectively.
\end{abstract}

Keywords: Static-PPP, GPS, GLONASS, Mixed observations, observation duration

\section{INTRODUCTION}

Global Positioning System (GPS) is a satellite-based structure for navigation and positioning. It has become the backbone of many aspects of our live and its applications, such as vehicle navigation, recreation, marine navigation, airborne navigation, time transfer, rescues, mapping, and missile guidance.

GPS technology offers different positioning techniques varying in cost and accuracy. A simple technique of positioning is called "autonomous positioning" which is the most flexible positioning form and is the original positioning technique that GPS was designed for. However, because of the errors caused by satellite ephemerides, satellite clock, ionosphere, troposphere, multipath and noise, the autonomous point positioning provides the user with a horizontal accuracy $\leq 13 \mathrm{~m}$ and a vertical accuracy $\leq 22 \mathrm{~m}$ (GPS-SPS, 2008).

To obtain higher accuracy down to the centimeter level, the user needs to mitigate the abovementioned errors by using the spatial correlation between one or more reference stations with known coordinates and the nearby rover GPS receiver station whose coordinates are to be determined. The GPS positioning technique that uses the concept of spatial correlation is known as Differential GPS (DGPS) (Abdel salam, 2005). The limitations for DGPS are; the need for a reference station, the distance limitation $(\leq 20 \mathrm{~km})$ between the rover and reference station, and the need for simultaneous observations between the reference and rover stations, which increases the cost of DGPS over autonomous positioning. 
The PPP technique (Zumberge et. al., 1997) aims at correcting the observations errors and overcoming the DGPS limitations. PPP is an enhanced single point positioning technique using code or phase measurements with precise orbits and clocks instead of broadcast data. PPP became viable with the existence of the extremely precise ephemerides and clock corrections, offered by different organizations such as the IGS (International GNSS Service). IGS has been providing the most precise satellite ephemerides and clock corrections currently available (IGS, 2013). To compensate for ionospheric effects (the largest source of error for GPS observations), dual frequency measurements are used for an ionosphere free combination. In the case of single frequency observations, some kind of ionosphere modeling has to be applied. For better accuracy, PPP users are advised with dual frequency measurements as it the most efficient way of mitigating ionospheric delay.

The PPP convergence period that is the length of time required from a cold start to a decimeter-level positional solution is typically about 30 minutes under normal conditions and will be significantly longer before the position solution can converge to the few centimeter level (Bisnath and Gao, 2008)._PPP accuracy improves with the length of the data collection period. A minimum period of good quality GPS data (no loss-of-lock) is required to permit convergence and/or resolving ambiguities, which in turn can improve the accuracy of the entire dataset. The minimum period and the accuracy attainable will depend on the type of GPS equipment, the site (multipath, obstructions) and atmospheric conditions. Extending the data collection period may further improve the attainable accuracy. The improvement in accuracy is more noticeable using dual-frequency receivers than single frequency receivers (Yves Mireault et al., 2008). The duration of collected observations should be decided according to the accuracy required.

Unfortunately, even with the modernized GPS system, there exist situations where the GPS signal may be partially obstructed, which in turn affect the availability and reliability of the PPP solution. To improve the availability, positioning accuracy and reliability of the PPP solution, it is recommended to combine the GPS and GLONASS constellations. GLONASS adds more satellites and improves availability and robustness. Combined systems (GPS/GLONASS) improve availability of satellite navigation in situations where part of the sky is blocked. This is the case close to oil rigs and during ionospheric disturbances (Changsheng Cai, 2009), (Russell David, 2010).

This research presents an evaluation study for the variability of Static-PPP precision based on different observation types (GPS, GLONASS and mixed observations) as well as different lengths of observation duration.

\section{TEST STUDY}

To assess Static-PPP precision variation based on different observation types (GPS, GLONASS and mixed observations) as well as different lengths of observation duration, an observation set of $6 \mathrm{hrs}$ (GPS day 17253) was tested for IGS station (barh) (IGS, 2013) with (LEICA GRX1200GGPRO) dual frequency receiver using $30 \mathrm{sec}$ observation interval and $10^{\circ}$ cut-off elevation angle. Each solution contains different lengths of observation duration (10 min., 20 min., $30 \mathrm{~min}, 45 \mathrm{~min} ., 1 \mathrm{hr}, 1.5 \mathrm{hr}, 2 \mathrm{hr}, 2.5 \mathrm{hr}, 3 \mathrm{hr}, 4 \mathrm{hr}$ and $6 \mathrm{hr}$ ). Management of observations files was done using the software TEQC "translate, edit, quality check" GNSS data tool (TEQC, 2013). The different sets of observations were processed and the PPP solutions were estimated through Canadian Spatial Reference System (CSRS) Precise Point Positioning (PPP) service (CSRS-PPP, 2013). 


\section{RESULTS \& DISCUSSION}

Tables 1, 2 and 3 present Static-PPP precision variation with observation duration for different observation types (GPS, GLONASS and mixed observations) resulting from this research. Figures 1, 2 and 3 Present graphical presentation for the Static-PPP precision variation with observation duration for different observation types (GPS, GLONASS and mixed observations) resulting from this research.

Table 1: Static-PPP accuracy variation with observation duration using GPS observations

\begin{tabular}{|c|c|c|c|}
\hline $\begin{array}{c}\text { Duration of } \\
\text { observations }\end{array}$ & \multicolumn{3}{|c|}{ Static-PPP accuracy variation using GPS observations } \\
\cline { 2 - 4 } & $\begin{array}{c}\text { Sigma (95\%) } \\
\text { Latitude (m) }\end{array}$ & $\begin{array}{c}\text { Sigma (95\%) } \\
\text { Longitude (m) }\end{array}$ & $\begin{array}{c}\text { Sigma (95\%) } \\
\text { Ellipsoidal } \\
\text { height (m) }\end{array}$ \\
\hline 10 min. & 0.767 & 1.117 & 1.516 \\
\hline 20 min. & 0.303 & 0.435 & 0.623 \\
\hline 30 min. & 0.170 & 0.232 & 0.366 \\
\hline 45 min. & 0.102 & 0.126 & 0.239 \\
\hline 1 hour & 0.075 & 0.084 & 0.190 \\
\hline 1.5 hour & 0.045 & 0.050 & 0.125 \\
\hline 2.0 hours & 0.027 & 0.040 & 0.083 \\
\hline 2.5 hours & 0.018 & 0.035 & 0.061 \\
\hline 3.0 hours & 0.014 & 0.034 & 0.052 \\
\hline 4.0 hours & 0.011 & 0.030 & 0.043 \\
\hline 6.0 hours & 0.007 & 0.020 & 0.029 \\
\hline
\end{tabular}

Table 2: Static-PPP accuracy variation with observation duration using GLONASS observations

\begin{tabular}{|c|c|c|c|}
\hline \multirow[t]{2}{*}{$\begin{array}{l}\text { Duration of } \\
\text { observations }\end{array}$} & \multicolumn{3}{|c|}{$\begin{array}{c}\text { Static-PPP accuracy variation using GLONASS } \\
\text { observations }\end{array}$} \\
\hline & $\begin{array}{l}\text { Sigma }(95 \%) \\
\text { Latitude (m) }\end{array}$ & $\begin{array}{l}\text { Sigma }(95 \%) \\
\text { Longitude }(\mathrm{m})\end{array}$ & $\begin{array}{c}\text { Sigma }(95 \%) \\
\text { Ellipsoidal } \\
\text { height }(\mathrm{m})\end{array}$ \\
\hline $10 \mathrm{~min}$. & 1.570 & 1.673 & 3.189 \\
\hline $20 \mathrm{~min}$. & 0.635 & 0.585 & 1.189 \\
\hline $30 \mathrm{~min}$. & 0.354 & 0.289 & 0.620 \\
\hline $45 \mathrm{~min}$. & 0.206 & 0.144 & 0.332 \\
\hline 1 hour & 0.145 & 0.089 & 0.229 \\
\hline 1.5 hour & 0.093 & 0.052 & 0.164 \\
\hline 2.0 hours & 0.052 & 0.037 & 0.115 \\
\hline 2.5 hours & 0.032 & 0.026 & 0.092 \\
\hline 3.0 hours & 0.023 & 0.021 & 0.077 \\
\hline 4.0 hours & 0.016 & 0.017 & 0.048 \\
\hline 6.0 hours & 0.009 & 0.016 & 0.033 \\
\hline
\end{tabular}


Table 3:Static-PPP accuracy variation with observation duration using mixed GPS/GLONASS observations

\begin{tabular}{|c|c|c|c|}
\hline \multirow{2}{*}{$\begin{array}{c}\text { Duration of } \\
\text { observations }\end{array}$} & \multicolumn{3}{|c|}{$\begin{array}{c}\text { Static-PPP accuracy variation using GPS/GLONASS } \\
\text { mixed observations }\end{array}$} \\
\cline { 2 - 4 } & $\begin{array}{c}\text { Sigma (95\%) } \\
\text { Latitude (m) }\end{array}$ & $\begin{array}{c}\text { Sigma (95\%) } \\
\text { Longitude (m) }\end{array}$ & $\begin{array}{c}\text { Sigma (95\%) } \\
\text { Ellipsoidal } \\
\text { height (m) }\end{array}$ \\
\hline 10 min. & 0.629 & 0.843 & 1.283 \\
\hline 20 min. & 0.256 & 0.322 & 0.475 \\
\hline 30 min. & 0.146 & 0.171 & 0.275 \\
\hline 45 min. & 0.088 & 0.092 & 0.168 \\
\hline 1 hour & 0.064 & 0.060 & 0.131 \\
\hline 1.5 hour & 0.040 & 0.037 & 0.093 \\
\hline 2.0 hours & 0.024 & 0.028 & 0.065 \\
\hline 2.5 hours & 0.016 & 0.021 & 0.051 \\
\hline 3.0 hours & 0.011 & 0.018 & 0.042 \\
\hline 4.0 hours & 0.008 & 0.013 & 0.029 \\
\hline 6.0 hours & 0.005 & 0.010 & 0.020 \\
\hline
\end{tabular}

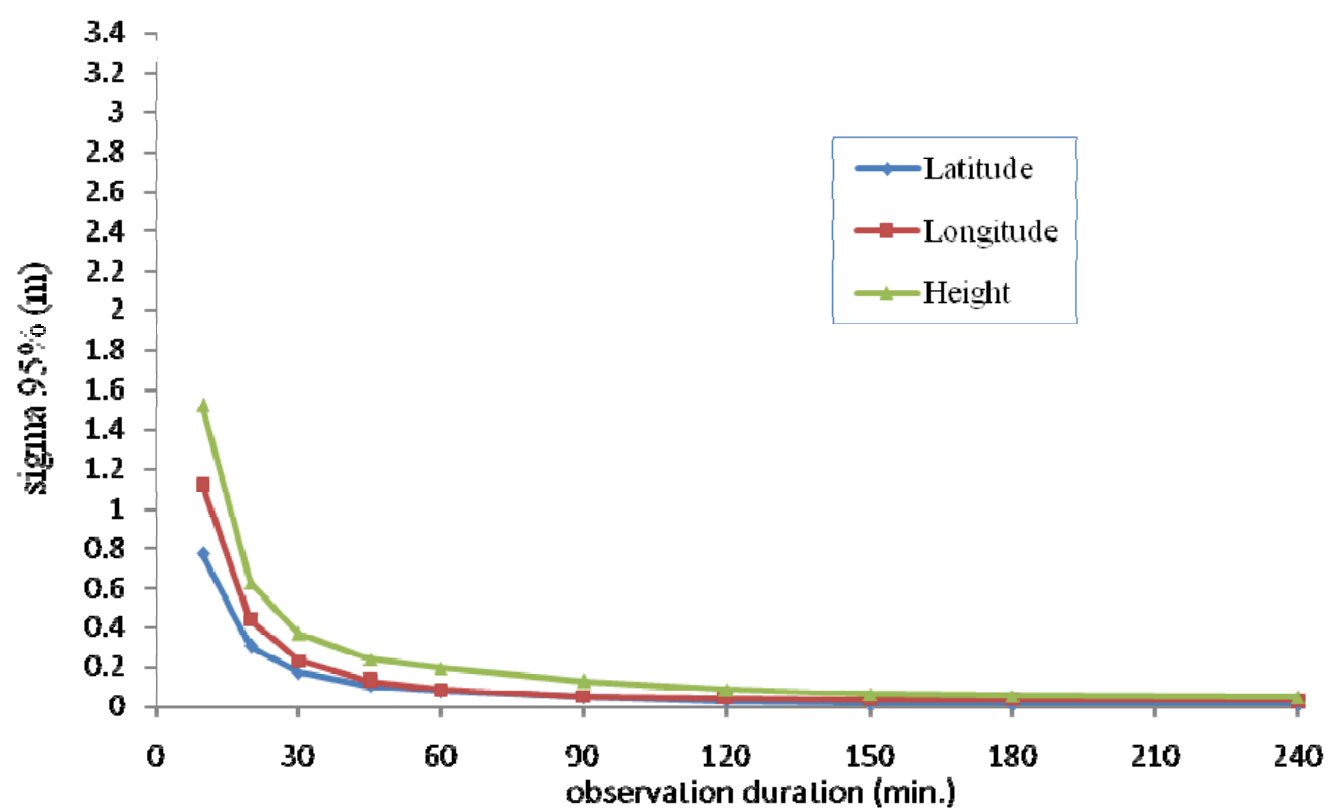

Fig. 1: PPP Positioning Precision as a function of observation duration for dual frequency (GPS static observations. 


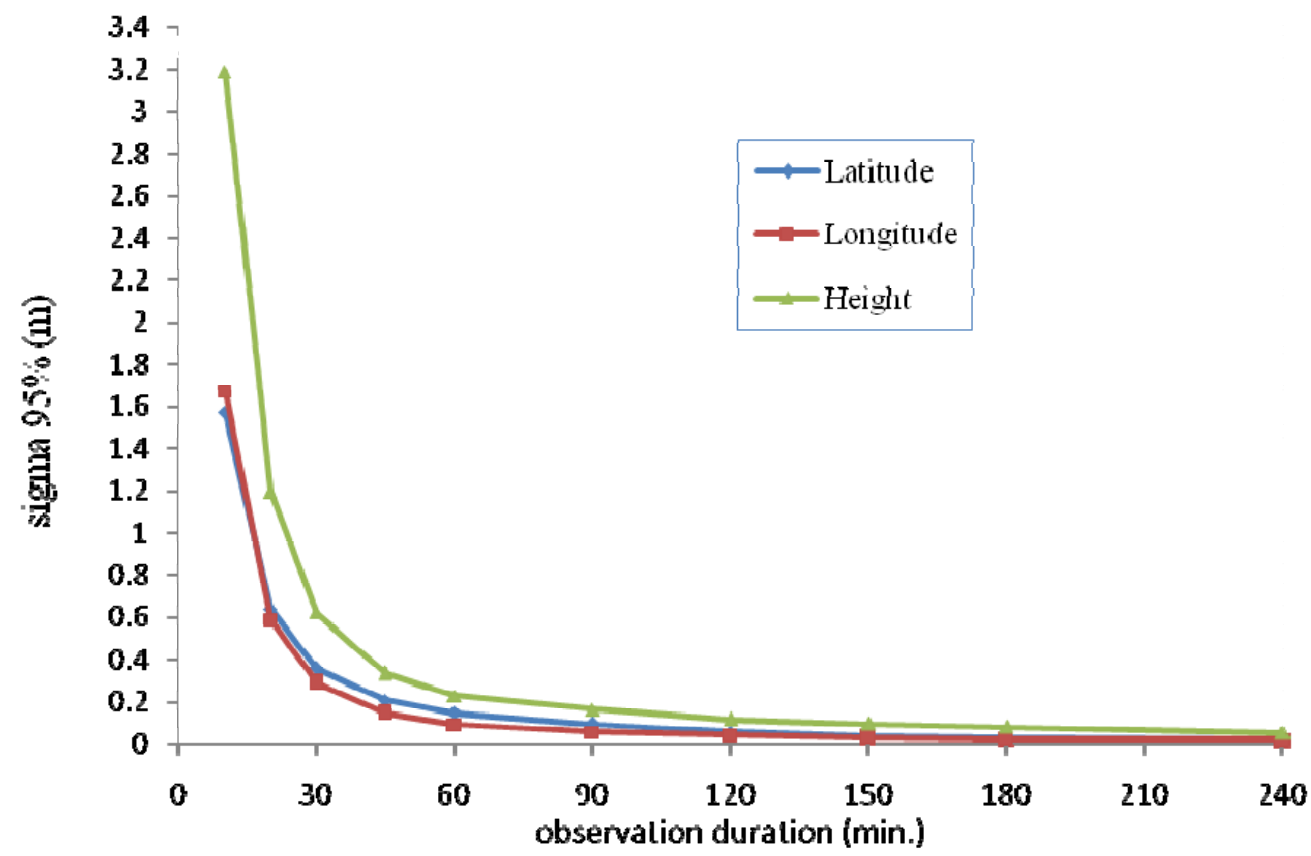

Fig. 2: PPP Positioning Precision as a finction of observation duration for dual frequency GLONASS static observations.

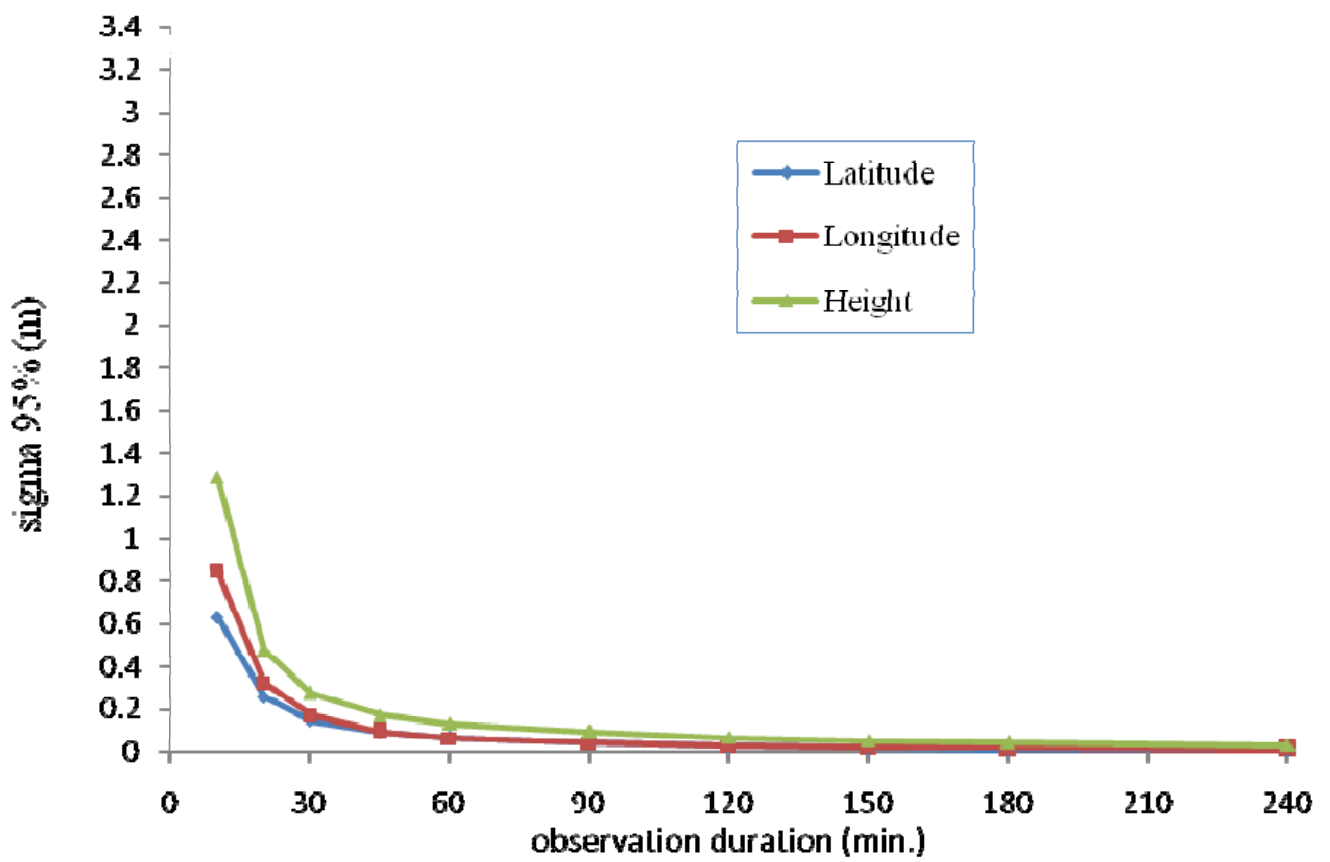

Fig. 3: PPP Positioning Precision as a function of observation duration for dual frequency mixed GPS/GLONASS static observations.

Table 4 presents improvement percentages in the precision of PPP-static solution in relation with observation duration for dual frequency mixed (GPS/GLONASS) observations over dual frequency GPS observations. 
Table 4: Improvement percentages in the precision of Static-PPP solution with observation duration for dual frequency mixed (GPS/GLONASS) observations over dual frequency GPS observations

\begin{tabular}{|c|c|c|c|}
\hline $\begin{array}{c}\text { Duration of } \\
\text { observations }\end{array}$ & \multicolumn{3}{|c|}{$\begin{array}{c}\text { Improvement percentages in the precision of Static-PPP solution with } \\
\text { observation duration for dual frequency mixed (GPS/GLONASS) } \\
\text { observations over dual frequency GPS observations }\end{array}$} \\
\cline { 2 - 4 } & $\begin{array}{c}\text { Latitude } \\
\text { improvement } \\
\text { percentage } \%\end{array}$ & $\begin{array}{c}\text { Longitude } \\
\text { improvement } \\
\text { percentage } \%\end{array}$ & $\begin{array}{c}\text { Ellipsoidal height } \\
\text { improvement } \\
\text { percentage } \%\end{array}$ \\
\hline 10 min. & 18 & 25 & 15 \\
\hline 20 min. & 16 & 26 & 24 \\
\hline 30 min. & 14 & 26 & 25 \\
\hline 45 min. & 14 & 27 & 30 \\
\hline 1 hour & 15 & 29 & 26 \\
\hline 1.5 hours & 11 & 26 & 22 \\
\hline 2.0 hours & 11 & 30 & 16 \\
\hline 2.5 hours & 11 & 40 & 33 \\
\hline 3 hours & 21 & 47 & 31 \\
\hline 4 hours & 27 & 57 & 319 \\
\hline 6 hours & 29 & 50 & 26 \\
\hline
\end{tabular}

The results shown in tables 1, 2 and 3 indicate the accuracy improvement of mixed observations over GPS-only observations for Static-PPP solution. The use of mixed observations typically results in similar precision as the use of GPS-only observations but needs 15 minutes less observation time.

Table 4 presents Improvement percentages in the precision of Static-PPP solution with observation duration for dual frequency mixed (GPS/GLONASS) observations over dual frequency GPS observations. For $1 \mathrm{hr}$ of observation duration, mixed observations offers improvement percentages of $15 \%, 29 \%$ and $31 \%$ for latitude, longitude and height respectively. For 4 hrs of observation duration, mixed observations offers better improvement percentages of $27 \%, 57 \%$ and $33 \%$ for latitude, longitude and height respectively.

\section{CONCLUSIONS}

This research presents an evaluation study for the variability of Static-PPP precision based on different observation types (GPS, GLONASS and mixed observations) as well as different lengths of observation duration. It proves that dual-frequency mixed observations gives better PPP solution precision comparing with dual frequency GPS observations. The reason for this is that the mixed GPS/GLONASS PPP solution can make use of extra GLONASS satellites to improve availability, position accuracy and reliability. Static-PPP solution using mixed observations is offering similar accuracy to the one using GPS observations and saving 15 minutes observation time.

Static-PPP solution precision depends on the observation duration where more length of observation duration improves the precision of the solution. Longer observation duration than $4 \mathrm{hrs}$ will not have noticeable effect. Better improvement percentages of $27 \%, 57 \%$ and $33 \%$ $\%$ in the precision of PPP-static solution for latitude, longitude and height respectively in relation with observation duration occur when using dual frequency mixed observations over dual frequency GPS observations. Those improvement percentages are expected to increase with the modernization of GLONASS constellation in the next few years. 


\section{REFERENCES}

Abdel salam (2005). Precise Point Positioning Using Un-Differenced Code and Carrier Phase Observations. Ph.D thesis, University of Calgary, Canada.

Bisnath S., Gao Y. (2008). Current State of Precise Point Positioning and Future Prospects and Limitations. International Association of Geodesy Symposia, Vol. 133 pp. 615-623, 2008.

Changsheng Cai (2009). Precise Point Positioning Using Dual-Frequency GPS and GLONASS Measurements. M.Sc. thesis, University of Calgary, Canada.

CSRS-PPP (2013). Canadian Spatial Reference System (CSRS) Precise Point Positioning (PPP) service.

http://www.geod.nrcan.gc.ca/products-produits/ppp_e.php. Accessed (10/5/2013).

GPS-SPS (2008). GPS standard positioning service (SPS) specifications. http://www.gps.gov/technical/ ps/2008-SPS-performance-standard.pdf. Accessed $(13 / 5 / 2013)$.

IGS (2013). International GNSS Service (IGS) station log. ftp://igs.org/pub/station/log/barh_20130805.log. Accessed (10/5/2013).

Katrin Huber and Florian Heuberger ( 2010). PPP: Precise Point Positioning - Constraints and Opportunities. FIG Congress 2010 (Facing the Challenges - Building the Capacity) Sydney, Australia, 11-16 April 2010.

PPP (2013). CSRS-PPP user guide. http://www.geod.nrcan.gc.ca/userguide/pdf/howtouse.pdf. Accessed (15/4/2013).

Russell David (2010). Improving Accuracy and Redundancy with GPS and GLONASS PPP. DYNAMIC POSITIONING CONFERENCE. October 12-13, 2010.

TEQC (2013). TEQC-UNAVCO tutorial. http://facility.unavco.org/software/teqc/doc/UNAVCO_Teqc_ Tutorial.pdf. Accessed $(5 / 5 / 2013)$.

Topcon GR-3 (2013). Topcon Positioning Systems ( GR-3). http://www.topconpositioning.com/legacy/gr-3. Accessed (20/4/2013).

Yves Mireault, Pierre Tétreault, François Lahaye, Pierre Héroux, and Jan Kouba (2008). online Precise Point Positioning: A New, Timely Service from Natural Resources Canada. GPS world magazine, September 2008.

Zumberge, J. F., M. B. Heflin, D. C. Jefferson, M. M. Watkins, and F. H. Webb (1997): Precise Point Processing for the Efficient and Robust Analysis of GPS Data from Large Networks, J. Geophys. Res., 102(B3), 5005-5017.

Received: 2013-12-09,

Reviewed: 2014-02-07,

Accepted: 2014-03-17. 